\title{
RETROPERITONEAL LAPAROENDOSCOPIC SINGLE-SITE APPROACH FOR RENAL CYST DECORTICATION - FIRST EXPERIENCE AND A REVIEW OF LITERATURE
}

\author{
NICOLAE CRISAN ${ }^{1}$, IULIA ANDRAS ${ }^{1}$, TEODORA TELECAN ${ }^{2}$, \\ ANDREEA SZABO ${ }^{3}$, ANDREI POPA ${ }^{3}$, RADU-TUDOR COMAN ${ }^{4}$, \\ PAUL MEDAN $^{3}$, IOAN COMAN ${ }^{1}$
}

\author{
${ }^{1}$ Urology Department, Iuliu Hatieganu University of Medicine and Pharmacy and \\ Clinical Municipal Hospital, Cluj-Napoca, Romania \\ ${ }^{2}$ Urology Department, Iuliu Hatieganu University of Medicine and Pharmacy, \\ Cluj-Napoca, Romania \\ ${ }^{3}$ Urology Department, Clinical Municipal Hospital Cluj-Napoca, Romania \\ ${ }^{4}$ Epidemiology Department, Iuliu Hatieganu University of Medicine and \\ Pharmacy, Cluj-Napoca, Romania
}

\begin{abstract}
Laparoendoscopic single-site (LESS) approach has been successfully employed for a number of urologic procedures. The retroperitoneal approach further limits the working space and instrument movement during LESS surgery, but has the advantage of a faster post-operative recovery and lower complications rate. We present our first experience using retroperitoneal LESS approach for a renal cyst decortication in a 40-year-old patient. The operative time was 40 minutes, the blood loss was minimal and we did not encounter significant conflicts between the instruments. The patient was discharged 2 days after the procedure and returned to full normal activity within one week. We consider that the retroperitoneal LESS approach is feasible for upper tract urologic surgery. Pre-bent instruments might further improve surgical gestures and extend the indications for more complex procedures. Nevertheless, the advent of reusable devices is expected to increase the cost-effectiveness of LESS and expand its use.
\end{abstract}

Keywords: laparoendoscopic single-site, retroperitoneal approach, upper urinary tract, renal cyst

\section{Introduction}

Laparoendoscopic single-site surgery (LESS) was successfully used for the first time in 2005 by Hirano et al [1] Since then, many single-port devices have been developed, both reusable and single use. As the experience in this new field increased, more and more complex pathologies have been tackled using LESS approach.

LESS surgery can be performed either by transperitoneal or retroperitoneal approach, the latter having the advantages of a faster post-operative recovery, lower complications rate and earlier hospital discharge [1]. On the other hand, the retroperitoneal approach is hampered by a smaller working space and not so familiar anatomy [2].

Renal cysts prevalence varies in the adult population between $20 \%$ and $50 \%$, the vast majority of them being

Manuscript received: 22.12.2017

Received in revised form: 22.01.2018

Accepted: 23.01.2018

Address for correspondence: dr.iuliaandras@gmail.com asymptomatic and undergoing regular surveillance [3]. Treatment of simple renal cysts is recommended when they associate flank pain, infection, obstruction of the pyelocaliceal system and hydronephrosis or impaired renal function. The treatment options for simple renal cysts are laparoscopic decortication or percutaneous aspiration-sclerotherapy (PAS). The percutaneous approach has shown lower success rates in comparison with the laparoscopic approach (60\% vs $96.6 \%)$ and currently it is not widely used, the surgical decortication being the recommended strategy [4].

As renal cyst decortication is a simple and fast procedure, we consider a minimally-invasive approach to be mandatory, with retroperitoneal LESS surgery offering the most advantages in terms of post-operative recovery, pain and complications rate.

\section{Case presentation}

A 40-year-old male patient presented to our department 
with a 12-month history of left lumbar pain, which he described as being dull, with an insidious onset. At presentation he was hemodynamically stable, without fever and did not recall any incident that might have caused the previously mentioned pain. On examination, a pseudotumoral, elastic mass could be palpated in the left upper quadrant. The ultrasound examination revealed a $9 \mathrm{~cm}$ transonic mass, located at the upper pole of the left kidney, which appeared to be a simple renal cyst.

The patient underwent a contrast-enhanced abdominal and pelvic computer tomography (CT), which showed a $9 / 7 / 8.5 \mathrm{~cm}$ cyst at the upper pole of the left kidney, on the anterior valve, with homogenous liquid content, thin, even walls and no apparent septations or calcifications (Figure 1). The CT also revealed a compressive effect of the cyst upon the left pyelocaliceal system, causing an upper pole hydrocalyx. Using the Bosniak classification [5], we graded the cyst as type I.

The patient underwent a pre-operative full check-up. A complete blood count and coagulation test were performed, as well as the standard liver and kidney function test panel, all of them being within the biological reference interval. No abnormality was detected while assessing the urinalysis and the urinary sediment.

\section{Surgical technique}

We describe the technique for the retroperitoneal approach, using a laparoendoscopic single site surgery device (GelPOINT, Applied MedicalResources Corp., Rancho, Santa Margarita, CA, USA). After the induction of general anesthesia, a Foley catheter was placed and the patient was rotated in $90 \mathrm{o}$ right lateral decubitus, with the surgical table bent at a 450 angle. The video cart was placed in front of the patient and the surgeon at the back. A small incision was performed on the mid-axillary line, above the left iliac crest and the retroperitoneal working space was developed by finger and Gaur balloon dissection.

The wound retractor was placed with the sealing lid on top, with the three working trocars passing through in the following manner: the trocar for the instrument on the right hand $(12 \mathrm{~mm})$ was placed at the bottom end of the anteriorposterior midline of the lid, while the trocar for the instrument on the left hand $(12 \mathrm{~mm})$ was placed at the top end, on the same axis. The optic trocar $(10 \mathrm{~mm})$ was positioned at the left end of the latero-lateral axis of the lid, thus leading to the triangular disposition (Figure 2).

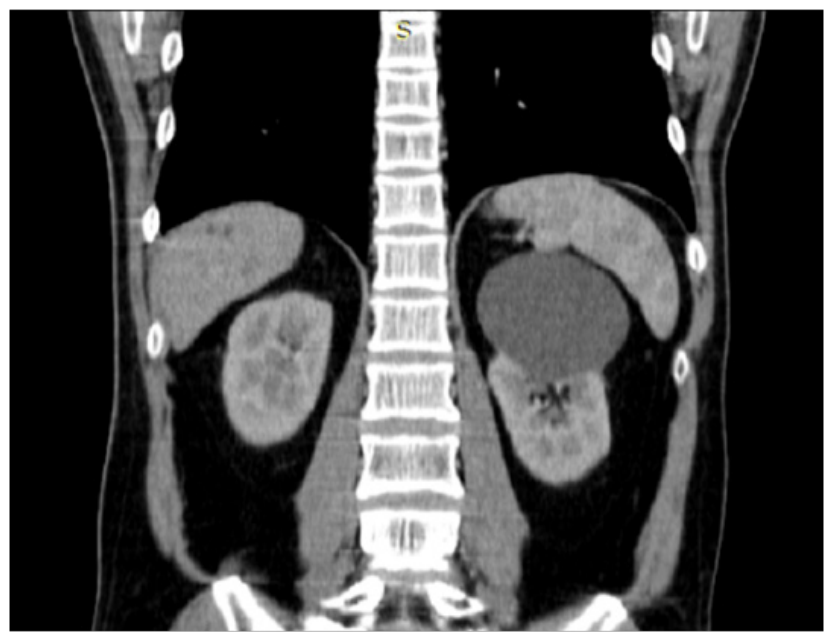

Figure 1. Arterial phase of abdominal CT image of the left renal cyst.
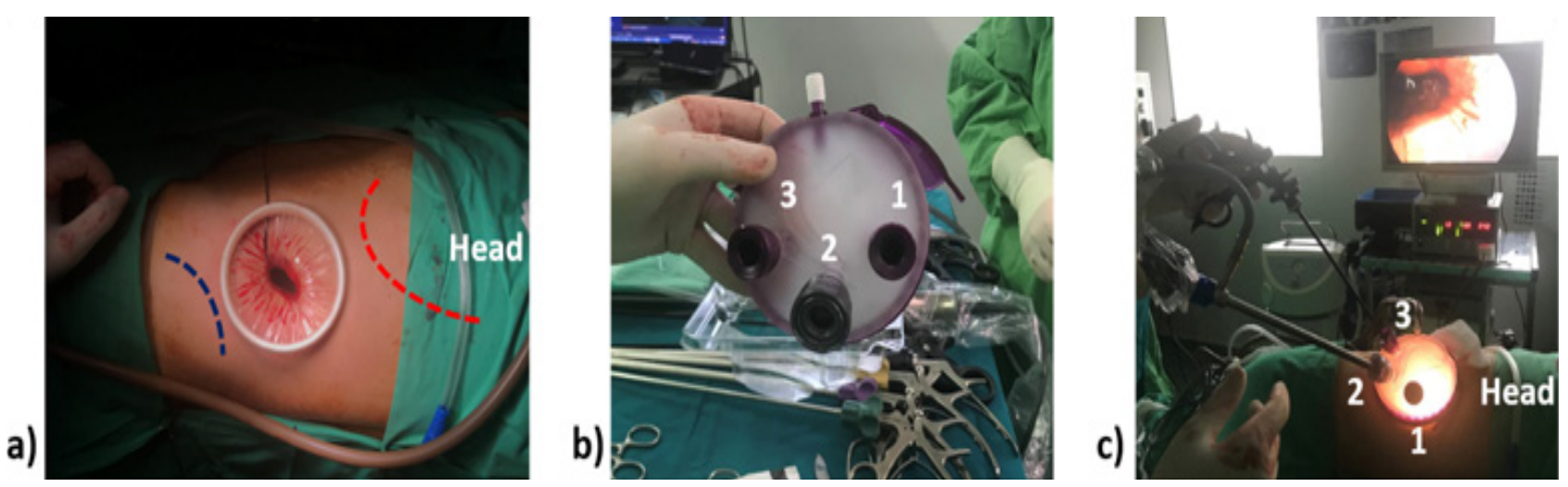

Figure 2. Retroperitoneal LESS approach for renal cyst decortication. a) the wound retractor is positioned on the mid-axillary line, above the iliac crest; the red line shows the costal margin, the blue line shows the iliac crest; b) the positioning of the trocars: 1. trocar for right hand, 2. optic trocar, 3. trocar for the left hand; c) exterior aspect of LESS surgery. 


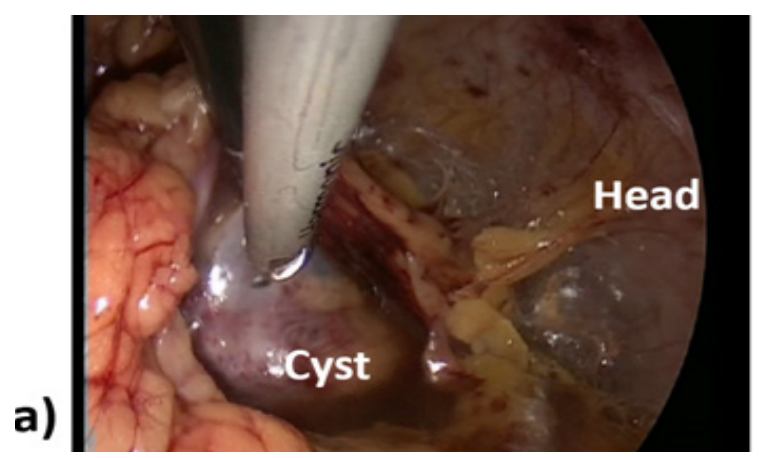

b)

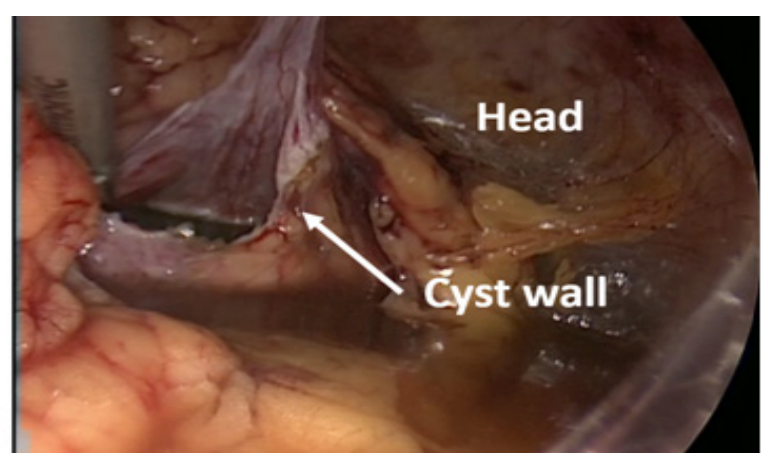

Figure 3. Intraoperative aspect of the retroperitoneal cavity. a) isolation of the renal cyst at the upper pole of the kidney; b) excision of the renal cyst wall .

The insufflation was performed up to a pressure of 12 mm Hg. A 300 laparoscope, a fenestrated forceps, a vascular sealer and a suction device were used for the procedure. The Gerota fascia was incised medially and the cyst was identified. The surrounding tissue was dissected and the cyst was incised (Figure 3). Approximately $300 \mathrm{ml}$ of serous citrine fluid were evacuated. The remaining cyst wall was removed from the kidney and sent for pathological analysis. The sealing lid was removed, along with the wound retractor. The blood loss was minimal. No drainage was placed.

The operative time was 40 minutes. We did not encounter significant conflicts between the instruments, and the working space allowed safe surgical gestures. The patient was mobilized the same day, regained bowel movements in the first post-operative day and was discharged on day 2 . There was no need for post-operative major analgesics and there were no post-operative complications. The patient returned to full activity after one week. The pathological examination revealed a benign renal cyst.

\section{Discussion}

Laparoendoscopic single-site surgery generates more and more interest among surgeons, not only for the immediate cosmetic effect provided by the small and solitary incision (about 2-3 cm), which can be easily hidden in pre-existing scars such as the umbilicus, but also for the reduced need of post-operative major analgesics, short recovery time and early hospital discharge [6].

\section{LESS surgery hurdles}

One of the main disadvantages of the single-port devices is that they are not reusable, therefore limiting the practicability of LESS surgery not only to the surgeon's experience and the patient's pathology, but also to the hospital's means and funds. As a result, large centers with increasing number of patients resorted to self-made devices [7]. Since the most problematic part is the sealing lid, this was replaced with a surgical glove. When insufflated, it provides up to 5 working channels, created by cutting the tip of the fingers and sealing the glove around the instrument with surgical thread. Other authors preferred to repurpose old instruments. Yang et al. [8] used a $10 \mathrm{~mm}$ operative laparoscope (Karl Storz, Tuttlingen, Germany) with a 6-mm working channel, similar to a nephroscope. Since this technique allows only one active instrument, it was limited to short and facile procedures, such as renal cyst decortication.

The X-Cone (Karl-Storz, Tuttlingen, Germany) is a reusable metallic LESS device, which was successfully employed by Schwentner et al. [9] in 29 patients. The main disadvantage of this system is that all instruments have to pass through a rigid channel with the diameter of $1.5 \mathrm{~cm}$, so prebent instruments are mandatory.

\section{Retroperitoneal approach for LESS surgery}

The preferred approach for LESS surgery is transperitoneal [10], taking into consideration that these devices have a series of restrictions in regards of the movements of the instruments. Due to the circular shape of the wound retractor and the sealing lid that constrict the instruments at the middle, the fulcrum effect is reduced, as well as the triangulation, while the clashing of the instruments is increased. Combined with the retroperitoneal approach, which provides a small working space, these two factors can put even a well-trained surgeon to a difficult test. Kaouk et al. [10] concluded that because of this impediment, an extra port may be required, or even a conversion to standard multiport laparoscopy techniques, due to the difficulty of dissection, failure to progress, difficult suturing and retraction in complex surgeries. As a result, the worldwide experience in retroperitoneal LESS surgery is rather limited.

Moreover, the learning curve can be steep and discouraging for many surgeons. Abdel-Karim et al. [11] analyzed a series of 179 patients who underwent LESS procedures performed by the same surgeon. The retroperitoneal approach was employed only for $7.2 \%$ of the cases, being considered a less suitable alternative, due to the space limitations. The most peri-operative complications were associated with the procedures that involved reconstructive surgeries, in comparison with ablative ones. The authors concluded that LESS can be performed safely by an experienced laparoscopic surgeon after a learning curve of at least 30 cases.

Retroperitoneal LESS surgery applications in urology

Despite the initial hindrances, retroperitoneal laparoendoscopic single-site surgery has been successfully used for both diagnosis and treatment purposes, for benign and malignant pathologies (Table I). Due to the reduced working space, a combination of conventional and pre-bent instruments might be preferable, especially for complex procedures. 
Table I. Outcomes of retroperitoneal LESS upper tract urologic surgery.

\begin{tabular}{|c|c|c|c|}
\hline Author, year & No of patients & Type of procedure & Reported outcomes \\
\hline Micali et al, 2014 [12] & 14 & Renal biopsy & $\begin{array}{l}\text { - } 100 \% \text { success rate } \\
\text { - No post-operative complications } \\
\text { - Minimal hospitalization: } 12-24 \text { hours }\end{array}$ \\
\hline Wang et al, 2016 [13] & $\begin{array}{l}\text { 51 LESS } \\
\text { vs } \\
65 \text { conventional } \\
\text { laparoscopy }\end{array}$ & $\begin{array}{l}\text { Adrenalectomy } \\
\text { (obese patients) }\end{array}$ & $\begin{array}{l}\text { - similar operative time, hospital length of stay and complications } \\
\text { - LESS group had significantly shorter incisions, lower analgesic } \\
\text { requirement and superior scar satisfaction score } \\
\text { - LESS is feasible for obese patients }\end{array}$ \\
\hline Tugcu et al, 2013 [14] & $\begin{array}{l}23 \text { LESS } \\
\text { vs } \\
42 \text { conventional } \\
\text { laparoscopy }\end{array}$ & Ureterolithotomy & $\begin{array}{l}\text { - similar operative time, blood loss and hospitalization time } \\
\text { - shorter duration of post-operative analgesia }(2.4 \text { days for LESS vs } \\
5.2 \text { days for conventional laparoscopy, } \mathrm{p}=0.001) \\
\text { - shorter time to return to normal activities }(6.4 \text { days for LESS vs } \\
9.7 \text { days for conventional laparoscopy, } \mathrm{p}=0.001)\end{array}$ \\
\hline Chen et al, 2012 [15] & 10 & Pyeloplasty & $\begin{array}{l}\text { - one conversion to multi-port laparoscopy } \\
\text { - combination of conventional and prebent instruments } \\
\text { - mean operative time of } 148.4 \text { mins } \\
\text { - mean hospitalization of } 5.7 \text { days } \\
\text { - one urine leakage treated conservatively } \\
\text { - satisfactory urinary drainage at } 3 \text { months }\end{array}$ \\
\hline Chen et al, 2012 [16] & 16 & Total nephrectomy & $\begin{array}{l}\text { - one conversion for adhesions due to genitourinary tuberculosis } \\
\text { - combination of conventional and pre-bent instruments } \\
\text { - mean operative time of } 85 \text { mins } \\
\text { - minimal blood loss } \\
\text { - mean hospital stay of } 4 \text { days }\end{array}$ \\
\hline Wu et al, 2014 [17] & 22 & Total nephrectomy & $\begin{array}{l}\text { - no conversions, no major complications } \\
\text { - combination of conventional and pre-bent instruments } \\
\text { - mean operative time of } 98 \text { mins } \\
\text { - minimal blood loss } \\
\text { - mean hospital stay of } 3.4 \text { days }\end{array}$ \\
\hline Nomura et al, 2011 [18] & 1 & $\begin{array}{l}\text { Radical } \\
\text { nephrectomy }\end{array}$ & $\begin{array}{l}\text { - hemodialyzed patient with acquired cystic kidney disease and two } \\
\text { renal masses } \\
\text { - LESS feasible for radical nephrectomy }\end{array}$ \\
\hline Dong et al, 2013 [19] & $\begin{array}{l}29 \text { LESS } \\
\text { vs } \\
29 \text { conventional } \\
\text { laparoscopy }\end{array}$ & $\begin{array}{l}\text { Radical } \\
\text { nephrectomy }\end{array}$ & $\begin{array}{l}\text { - self-made LESS device } \\
\text { - similar operative time, blood loss and complications rate } \\
\text { - LESS had a shorter duration of hospitalization }(7.14 \text { days vs } 8.17 \\
\text { days, } p=0.009)\end{array}$ \\
\hline
\end{tabular}

\section{Retroperitoneal LESS renal cyst decortication}

This case-report presents our department's first experience with retroperitoneal laparoscopic single-port surgery, using a non-reusable device (GelPOINT). We consider that retroperitoneal LESS is feasible for renal cyst decortication, as this surgery requires linear movements, in a back and forth fashion, thus minimizing the clashing of the instruments inside the retroperitoneal cavity. Ample, circular movements needed for large dissection and suturing may be hampered using this approach because of the permanent contact of the instruments. In our case, we did not encounter significant conflict of the instruments, although we used only conventional rigid laparoscopic instruments.

Similar experience was also described by Yang et al. [8] and by Chen et al. [20]. However, they used an operative laparoscope, allowing them to use only one instrument at a time. The authors suspended the cyst using a percutaneous suture. While Yang et al. [8] chose the same position of the single-port device, Chen et al. [20] placed it halfway between the ipsilateral costal margin and the iliac crest. Both authors reported a similar operating time to our experience (a mean of 49 and 60 minutes, respectively), but a longer hospitalization (3 days) than in our patient, who was discharged on the second day after surgery.

Although it has shown a number of advantages for the patients, not only in the immediate peri-operative period, but also at 3 and 6 months follow-up, the retroperitoneal LESS technique remains challenging for the surgeon, especially in complex cases.

A transperitoneal approach with an umbilical singleport trocar would have been a scar-less alternative for renal cyst decortication, but we consider that the risk of intraand post-operative complications (bowel lesions, ileus) is 
higher for the transperitoneal access. Another alternative would have been to perform the laparoscopic renal cyst decortication using $5 \mathrm{~mm}$ laparoscopic instruments and camera. Further studies are needed in order to emphasize the advantages of both techniques.

\section{Conclusions}

The retroperitoneal LESS approach for renal cyst decortication is feasible, with acceptable conflicts between the instruments and working space. Pre-bent instruments might further improve surgical gestures and extend the indications to more complex procedures. Ablative procedures seem to be more suitable for this technique, but a thorough selection of the patients is needed in order to demonstrate the best results. Nevertheless, the advent of reusable devices is expected to increase the costeffectiveness of LESS and extend its use.

\section{References}

1. Hirano D, Minei S, Yamaguchi K, Yoshikawa T, Hachiya T, Yoshida T, et al. Retroperitoneoscopic adrenalectomy for adrenal tumors via a single large port. J Endourol. 2005;19:788-792.

2. Crisan N, Neiculescu C, Matei DV, Coman I. Robotic retroperitoneal approach - a new technique for upper urinary tract and adrenal gland. Int J Med Robot 2013;9:492-496.

3. Rané A. Laparoscopic management of symptomatic simple renal cysts. Int Urol Nephrol. 2004;36:5-9.

4. Bas O, Nalbant I, Can Sener N, Firat H, Yeşil S, Zengin $\mathrm{K}$, et al. Management of renal cysts. JSLS. 2015 JanMar;19(1):e2014.00097. doi: 10.4293/JSLS.2014.00097.

5. Bosniak MA. Diagnosis and management of patients with complicated cystic lesions of the kidney. AJR Am J Roentgenol. 1997;169:819-821.

6. Autorino R, Cadeddu JA, Desai MM, Gettman M, Gill IS, Kavoussi L, et al. Laparoendoscopic single-site and natural orifice transluminal endoscopic surgery in urology: a critical analysis of the literature. Eur Urol. 2011;59:26-45.

7. Lee SW, Lee JY. Laparoendoscopic single-site urological surgery using a homemade single port device: the first 70 cases performed at a single center by one surgeon. J Endourol. 2011;25:257-264.

8. Yang D, Xue B, Zang Y, Liu X, Zhu J, Chen D, et al. A modified laparoendoscopic single-site renal cyst decortication: singlechannel retroperitoneal laparoscopic decortication of simple renal cyst. J Laparoendosc Adv Surg Tech A. 2013;23:506-510.
9. Schwentner C, Todenhöfer T, Seibold J, Alloussi SH, Aufderklamm S, Mischinger $\mathrm{J}$, et al. Upper urinary tract laparoendoscopic single-site surgery based on a novel costeffective reusable platform. J Endourol. 2013;27:202-207.

10. Kaouk JH, Autorino R, Kim FJ, Han DH, Lee SW, Yinghao S, et al. Laparoendoscopic single-site surgery in urology: worldwide multi-institutional analysis of 1076 cases. Eur Urol. 2011;60:9981005.

11. Abdel-Karim AM, Elhenawy IM, Eid AA, Yahia E, Elsalmy SA. Laparoendoscopic single-site surgery for the treatment of different urological pathologies: Defining the learning curve of an experienced laparoscopist. Arab J Urol. 2017;15:187-193.

12. Micali S, Zordani A, Galli R, Martorana E, Piccoli M, Cappelli G, et al. Retroperitoneoscopic single site renal biopsy surgery: right indications for the right technique. BMC Urol. 2014 Oct 13;14:80. doi: 10.1186/1471-2490-14-80.

13. Wang $\mathrm{Y}, \mathrm{He} \mathrm{Y}, \mathrm{Li}$ BS, Wang $\mathrm{CH}$, Chen $\mathrm{Z}, \mathrm{Lu} \mathrm{ML}$, et al. Laparoendoscopic single-site retroperitoneoscopic adrenalectomy versus conventional retroperitoneoscopic adrenalectomy in obese patients. J Endourol. 2016;30:306-311.

14. Tugcu V, Simsek A, Kargi T, Polat H, Aras B, Tasci AI. Retroperitoneal laparoendoscopic single-site ureterolithotomy versus conventional laparoscopic ureterolithotomy. Urology. 2013;81:567-572.

15. Chen Z, Chen X, Wu ZH, Luo YC, He Y, Li NN, et al. Feasibility and safety of retroperitoneal laparoendoscopic singlesite dismembered pyeloplasty: a clinical report of 10 cases. J Laparoendosc Adv Surg Tech A. 2012;22:685-690.

16. Chen Z, Chen X, Luo YC, He Y, Li NN, Xie CQ, et al. Retroperitoneal laparoendoscopic single-site simple nephrectomy: initial experience. J Endourol. 2012;26:647-651.

17. Wu Z, Xu Y, Yu J, Chen J, Liu J, Wang S, et al. Laparoendoscopic single-site retroperitoneoscopic nephrectomy for giant hydronephrosis. J Endourol. 2014;28:1328-1332.

18. Nomura T, Sato F, Takahashi M, Sumino Y, Mimata H. Laparoendoscopic single-site (LESS) retroperitoneal radical nephrectomy in a patient with renal cell carcinoma receiving hemodialysis. Case Rep Med. 2011;2011:506032. doi: 10.1155/2011/506032.

19. Dong J, Zu Q, Shi L, Gao J, Song T, Li H, et al. Retroperitoneal laparoendoscopic single-site radical nephrectomy using a lowcost, self-made device: initial experience with 29 cases. Surg Innov. 2013;20:403-410.

20. Chen D, Xue B, Shan Y, Yang D, Sun C. Retroperitoneal laparoendoscopic single-site surgery by single trocar technique: initial experience with renal cyst decortication. J Laparoendosc Adv Surg Tech A. 2012;22:972-977. 